\title{
Is intra-bladder pressure measurement a reliable indicator for raised intra-abdominal pressure? A prospective comparative study
}

\author{
Abdulla Ahmed Al-Abassi ${ }^{*}$ (D), Azan Saleh Al Saadi ${ }^{1}$ and Faisal Ahmed ${ }^{2}$
}

\begin{abstract}
Background: Intra-abdominal pressure (IAP) can be measured by several indirect methods; however, the urinary bladder is largely preferred. The aim of this study was to compare intra-bladder pressure (IBP) at different levels of IAPs and assess its reliability as an indirect method for IAP measurement.

Methods: We compared IBP with IAP in twenty-one patients undergoing laparoscopic cholecystectomy under general anesthesia. Measurements were recorded at increasing levels of insufflation pressures to approximately $22 \mathrm{mmHg}$. Pearson's correlation coefficient was calculated to establish the relationship between the two pressure measurements and Bland-Altman analysis was used to assess the limits of agreement between the two methods of measurements.

Results: The urinary bladder pressures reflected well the pressures in the abdominal cavity. Pearson correlation coefficient showed a good correlation between the two measurement techniques ( $r=0.966, p<0.0001)$ and BlandAltman analysis indicated that the $95 \%$ limits of agreement between the two methods ranged from -2.83 to 2.64 . This range is accepted both clinically and according to the recommendations of the World Society of Abdominal Compartment Syndrome (WSACS).

Conclusion: Our study showed that IBP measurement is a simple, minimally invasive method that may reliably estimates IAP in patients placed in supine position. Measurements for pressures higher than $12 \mathrm{mmHg}$ may be less reliable. When applied clinically, this should alert the clinician to take safety measures to avoid abdominal compartment syndrome (ACS).
\end{abstract}

Keywords: Intra-abdominal pressure, Urinary bladder pressure, Intra-vesical pressure, Compartment syndrome, Intraabdominal hypertension

\section{Background}

Intra-abdominal Hypertension (IAH) is defined as an intra-abdominal pressure (IAP) equal to or above $12 \mathrm{mmHg}$ and abdominal compartment syndrome (ACS) is defined as an IAP above $20 \mathrm{mmHg}$ with evidence of organ dysfunction/failure [1]. Both levels of increased intra-abdominal tension are known to causes significant morbidity and mortality among critically ill patients. This includes acute renal failure, pulmonary impairment, and reduced blood flow to the gastro-intestinal organs $[1,2]$. In addition, increased IAP can cause elevation of the diaphragm with consequent increase in intra-thoracic

\footnotetext{
* Correspondence: alabassi@hotmail.com

${ }^{1}$ Department of Surgery, Saqr Hospital, Ras Al Khaimah, United Arab Emirates Full list of author information is available at the end of the article
}

pressure, which has a major effect on pulmonary compliance [3]. The high intra-thoracic pressure may interfere with the cerebral venous return via the jugular venous system leading to intra-cranial congestion and brain dysfunction [4].

Clinically, significant intra-abdominal hypertension may be present in the absence of abdominal distension [5]. Therefore, increased IAP is commonly measured by recording urinary bladder pressure (IBP). Kron et al. were the first to describe this technique in 1984 [2]. Later, Cheatham and Safcsak revised this technique by creating a system that was entirely closed, thus making the process of serial bedside IAP determinations easier, safer, and unlikely to introduce bladder infection [6].

(c) The Author(s). 2018 Open Access This article is distributed under the terms of the Creative Commons Attribution 4.0 International License (http://creativecommons.org/licenses/by/4.0/), which permits unrestricted use, distribution, and 
The reliability of the urinary bladder as an indirect tool for measuring the IAP clinically is not agreed upon and human studies correlating IAP and IBP are scarce and far from being accurate and reproducible [5]. Supporting evidence comes from Fusco et al. [6] who found that the IBP closely approximates IAP in 37 patients. On the other hand, Johna et al. [4] found that IBP did not reflect the actual IAP in a clinical study of 21 patients undergoing laparoscopic cholecystectomy. Yol et al. [7] found that the IBP correlated well with the insufflator pressure in 40 patients undergoing laparoscopic cholecystectomy. However, the last two studies lack statistical accuracy, and their methodologically has been criticized $[5,8]$. Moreover, techniques of simulating increased IAP via instillation of normal saline or insufflation of carbon dioxide as in laparoscopy are far from being an ideal environment for extrapolation to critically ill patients.

Our study aimed to determine the reliability of IBP measurement as an indirect measure of IAP. We conducted a prospective study in 21 patients undergoing laparoscopic cholecystectomy. We measured the IAP and IBP by gradually increasing the insufflator pressure to normal, then to high IAP of approximately $22 \mathrm{mmHg}$ for a very short period to avoid any deleterious effects on patients' hemodynamics. The use of such high pressure is based on the recommendations of the WSACS [8] and the study of Fusco et al. [6] who used insufflation pressures up to $25 \mathrm{mmHg}$ without risking patient safety. We took into consideration the recommendations suggested by Malbrain M. [5] like proper positioning of the patient, the ideal fluid volume instilled into the bladder, proper positioning of the pressure transducers, and avoiding IAP measurement via Veress needles. In addition, statistical recommendations of the World Society of Abdominal Compartment Syndrome (WSACS) have generally been fulfilled $[8,9]$.

\section{Methods}

This study was conducted at Saqr Hospital, Ras Al Khaimah, United Arab Emirates, in accordance with the study protocol approved by the hospital research ethics committee. All patients consented for participation in the study and agreed for publishing study results in medical journals.

Twenty-one patients aged 21-54 years and undergoing laparoscopic cholecystectomy between January and August 2007 were recruited for the study. Consenting for IBP and IAP measurements under general anesthesia were obtained. Patients with urinary symptoms, urinary bladder diseases, history of heart disease or chronic pulmonary disease were excluded. Pregnant women and children were also excluded.

Bladder pressure measurements were conducted by using DantecMenuet equipment (M 247) and fluid-filled lines with external pressure transducers. An 8 F double-lumen pressure catheter was introduced into the urinary bladder transurethral under sterile conditions. One lumen was used to evacuate the bladder and infuse $50 \mathrm{ml}$ of normal saline at room temperature. The other lumen was used for pressure measurement. A $10 \mathrm{~F}$ single-lumen pressure catheter with a balloon tip connected to a pressure transducer was then introduced through the epigastric port and the balloon tip is placed intraperitoneally under direct vision. The catheter has a 3-way extension through which the balloon is filled with normal saline and after evacuation of air the fluid is retained in the syringe. Once the catheter is placed in the abdomen the fluid is flushed back into the balloon. The transducer tubings are infused with normal saline to evacuate the air and calibrated to zero pressure before connecting to the urethral pressure catheter.

All pressure measurements were performed with the patients lying in supine position under general anesthesia before starting laparoscopic cholecystectomy. The level of the symphysis pubis has been chosen for calibrating the pressure transducers for its simplicity to localize, taking into consideration that the mid axillary line is difficult to identify with the patient draped under general anesthesia. Zero balancing (calibrating the transducer's output signal at zero pressure) was performed at atmospheric pressure with a stabilizing period of about 3 min before taking pressure measurements. Once the connections are made, to avoid any artifacts, the pressure lumen catheters are flushed with a minimal amount of saline through the transducer channel to avoid any air bubble or gel interruption.

The baseline IAP and IBP measurements are pressures recorded when no air insufflations applied to the abdomen. The two pressure measurements were then simultaneously recorded by stepwise increment of IAP by increasing the insufflation pressure gradually to approximately $22 \mathrm{mmHg}$, as shown on the laparoscopy $\mathrm{CO} 2$ insufflator. The readings are detected by DantecMenuet equipment and documented internally as the pressure goes up. We allowed a short period of stabilization before each reading. The number of readings and the level of pressures at each reading measured were not predefined and are not the same for each patient. Intra-peritoneal cavity then gradually deflated, the recording measurements took approximately 10 $15 \mathrm{~min}$, the catheters were removed and laparoscopic cholecystectomy was performed. The data collected from the system memory was transmitted to a computer and saved for later analysis.

\section{Statistics}

Pearson's correlation coefficient ( $r$ ) was calculated to assess the strength of relation between IAP and IBP 
measurements. For quantitative analysis. Agreement between the two methods of measurements was assessed and plotted using Lin' concordance correlation coefficient (LCCC) [10] and Bland-Altman method [11]. Internal consistency for all measurements was assessed using Cronbach's $\alpha$ coefficient [12] with cut-offs of .8 denoting good and .9 denoting excellent reliability. Although not universally agreed upon, we used the descriptive scale suggested by McBride [13] to interpret the LCCC for strength of agreement. In Bland-Altman method, differences between the two methods are plotted against their averages. Horizontal lines indicate the mean difference (bias) and $\pm 1.96 \times$ the standard deviation. This is useful to calculate and visualize the trend of the differences.

Statistical analyses and figures produced for all pairs of data were performed using "Medcalc" version 12.7 (Medcalc Software, Mariakerke, Belgium) and Statistical Package for the Social Sciences (SPSS, version 21; IBM, New York, NY, USA). SPSS was also used to convert all pressure measurements, which were recorded in $\mathrm{cmH}_{2} \mathrm{O}$, to mmHg using the SPSS 'transform' tab before data analysis (conversion coefficient $=0.735$ ).

\section{Results}

Twenty-one patients aged 21-54 (Average 31.8) years underwent laparoscopic cholecystectomy. Twenty were female patients (95\%). All 21 patients completed their surgery without any consequences from our intervention and had uneventful postoperative period.

Three hundred and eighty eight simultaneous pressure measurements from all 21 patients were recorded at varying IAPs. Out of these measurements, $20.9 \%$ were above $12 \mathrm{mmHg}$ (IAH) and $3.1 \%$ were above $20 \mathrm{mmHg}$ (grade III IAH).

When the IAP was elevated by intra-peritoneal carbon dioxide $\left(\mathrm{CO}_{2}\right)$ insufflation to approximately $22 \mathrm{mmHg}$, the IBP showed parallel increments to about the same levels. Similarly, during gradual deflation of $\mathrm{CO}_{2}$ and reduction of the IAP to about $0 \mathrm{mmHg}$, IBP showed a comparable decrease to about the same level as the IAP.

Pearson correlation coefficient showed a strong correlation between the two measurements $(r=0.966$, $p<0.0001$ ) (Table 1).

Scatter plot diagram with line of identity for the Lin's concordance correlation between the two methods is depicted in (Fig. 1).

The Bland-Altman analysis indicates that the $95 \%$ limits of agreement between the two methods of measurement ranged from -2.83 to 2.64 , the mean of the difference between the two methods (Bias) is -0.096 , and the standard deviation of the bias (precision) is 1.395 (Table 2).

This indicates that the two methods provide similar measures because the level of agreement lies within the accepted range, both clinically and according to the recommendations of the WSACS [8]. The percentage difference or the coefficient of variation (defined as the precision divided by mean IAP is $11.89 \%$, (should be no higher than $15-20 \%$ according to the recommendations of the WSACS [8]). Bland-Altman Scatter Diagram for the difference between the two methods is illustrated in (Fig. 2).

Likewise, Pearson correlation coefficient and Bland-Altman analysis were calculated for IAP greater than $12 \mathrm{mmHg}$ (IAH) (Tables 1 and 2, Figs. 1 and 2). Both showed comparable results that are accepted both clinically and according to the recommendations of the WSACS. The Bland-Altman analysis indicates that the 95\% limits of agreement between the two methods of measurement ranged from -0.62 to 0.05 , the mean of the difference between the two methods (Bias) is 0.281 , and the standard deviation of the bias (precision) is 1.395 (Table 2).

Lin's Concordance correlation coefficient (LCCC) between the two measurements was 0.965 (95\% confidence

Table 1 Lin's Concordance \& Pearson Correlation Coefficients between the two methods: IAP \& IBP for all measures (IAP =0-22 mmHg) Versus High IAP (IAP > 12 mmHg)

\begin{tabular}{lll}
\hline Variable $Y$ & Intra Abdominal Pressure (IAP =0-22 mmHg) & Intra Abdominal Pressure (IAP > 12 mmHg) \\
Variable $X$ & Intra Bladder Pressure (IBP with IAP =0-22 mmHg) & Intra Bladder Pressure (IBP with IAP $>12 \mathrm{mmHg}$ ) \\
Sample size & 388 & 81 \\
Mean & IAP: 8.254 & IAP: 16.173 \\
& IBP: 8.351 & IBP: 16.455 \\
Variance & IAP: 27.037 & IAP: 09.150 \\
& IBP: 29.318 & IBP: 15.764 \\
Concordance correlation coefficient & 0.965 & 0.903 \\
95\% Confidence interval & 0.958 to 0.971 & 0.866 to 0.931 \\
Pearson $\rho$ (precision) & 0.966 & 0.940 \\
Significance level & $P<0.0001$ & $P<0.0001$ \\
Bias correction factor $C_{b}$ (accuracy) & 0.999 & 0.961 \\
\hline
\end{tabular}


a

IAP measurements 0-22 mmHg

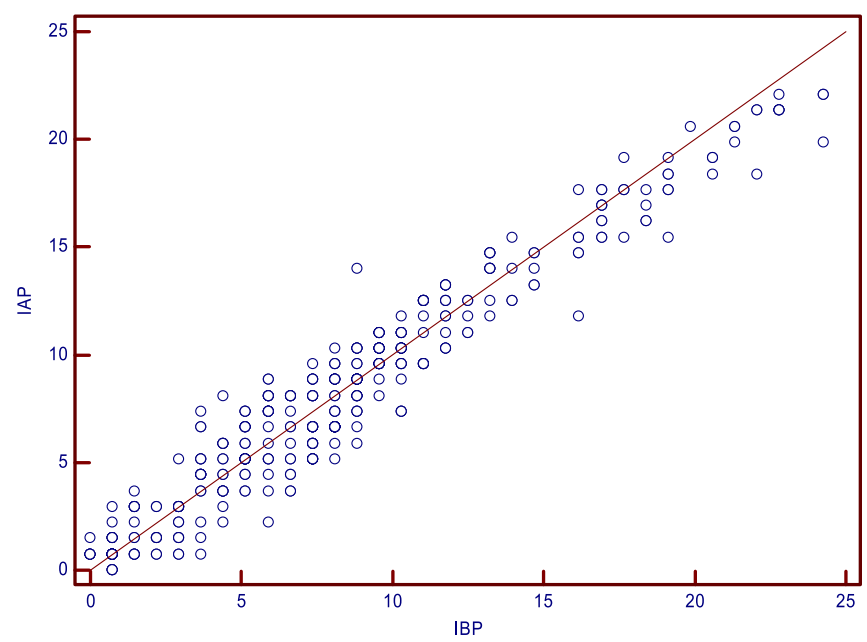

b IAP measurements $>12 \mathrm{mmHg}$

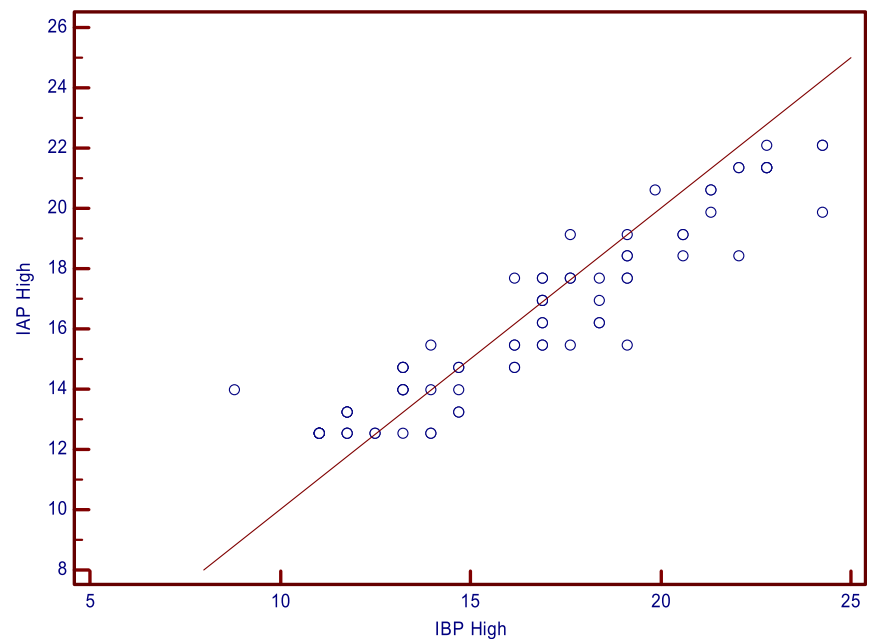

Fig. 1 Scatter plot with line of identity for Lin's Concordance Correlation between the two methods: a IAP measurements $0-22 \mathrm{mmHg}$; b IAP measurements $>12 \mathrm{mmHg}$

interval: 0.95-0.97) (Table 1). A scatter plot of the measurements with line of identity is represented in (Fig. 1). This shows a "substantial" strength of agreement based on the descriptive scale suggested by McBride for interpreting LCCC [12]. LCCC for high measurements (IAP > $12 \mathrm{mmHg}$ ) was 0.90 (95\% confidence interval: $0.87-$ 0.93) (Table 1), which indicates a "moderate" strength of agreement based on the descriptive scale suggested by McBride [12]. A scatter plot of the measurements with line of identity is represented in (Fig. 1b). This implies that intra bladder pressure measurements for higher pressures higher than $12 \mathrm{mmHg}$ may be less reliable, according to McBride, for the early detection of intra-abdominal hypertension.

Likewise, Cronbach's alpha for estimating internal consistency reliability for all measurements including subsets for high (IAP > $12 \mathrm{mmHg}$ ) and very high (IAP > $20 \mathrm{mmHg}$ ) measurements. Internal consistency reliability was excellent for all measurements as well as high measurements (Cronbach's alpha $=0.98$ and .95 respectively), but only acceptable for very high measurements (Cronbach's alpha $=0.79)$ (Table 3$)$, most likely because of the smaller number of measurements (IAP > $20 \mathrm{mmHg}, 12 / 388$ ).

\section{Discussion}

The consequences of increased IAP and ACS are well known and are a source of significant morbidity and mortality in critically ill patients $[1,4,6]$. Therefore, the ability to determine IAP by a simple, reliable and non-invasive technique is of vital importance for the proper management of critically ill patients with IAH, 
a

IAP measurements 0-25 mmHg

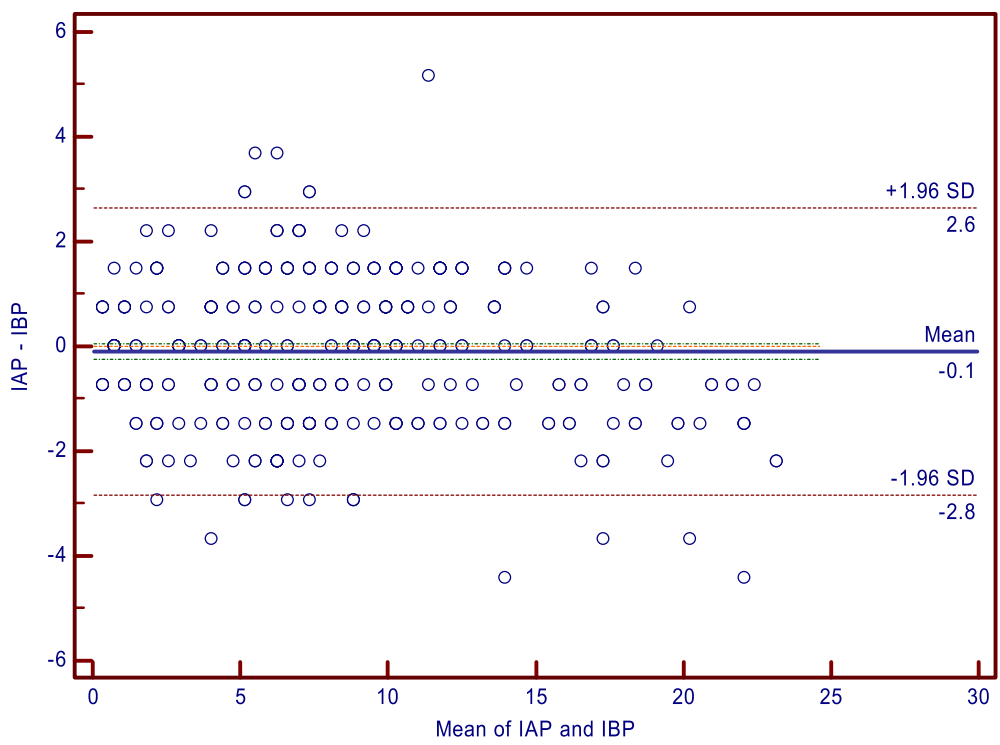

b IAP measurements $>12 \mathbf{~ m m H g}$

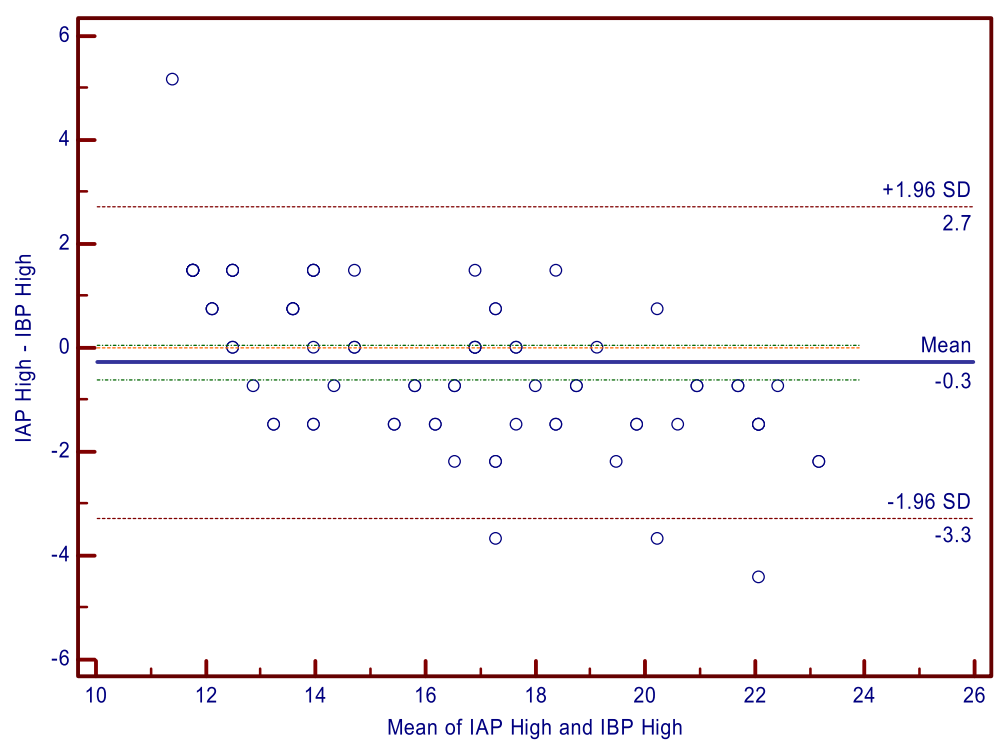

Fig. 2 Bland-Altman Scatter Diagram for the two methods: a IAP measurements 0-25 mmHg; b IAP measurements $>12 \mathrm{mmHg}$

and taking the necessary measures to avoid the occurrence of ACS.

Urinary bladder pressure measurement is the most widely used technique as an indirect method for IAP assessment, but the accuracy and reproducibility are not well established among researchers [5]. Most of their resources come from animal lab studies, the validity of which is questioned because of considerable anatomical differences from humans. One of the major variations is that the bladder being mostly intra-peritoneal in studied animals $[2,6]$.
Indirect measurements of IAP are position dependent and may not correlate well with the IAP except in the supine position where the mean increment in bladder pressure reflected most closely the IAP [3]. Although not widely accepted, the presence of air-bubbles in the fluid-filled system may partly account for measurement inaccuracy leading to over- or under-estimation $[5,14]$. In our study, all pressure measurements were performed with the patients lying in supine position and the pressure transducers zero reference level placed at the 
Table 2 Bland-Altman Analysis for the two methods: IAP \& IBP for all measures (IAP = 0-22 mmHg) Versus measures for High IAP $(\mathrm{IAP}>12 \mathrm{mmHg})$

\begin{tabular}{|c|c|c|}
\hline First measurement [Method A] & Intra Abdominal Pressure (IAP $=0-22 \mathrm{mmHg})$ & Intra Abdominal Pressure (IAP > 12 mmHg) \\
\hline Second measurement [Method B] & Intra Bladder Pressure (IBP with IAP $=0-22 \mathrm{mmHg}$ ) & Intra Bladder Pressure (IBP with IAP > $12 \mathrm{mmHg}$ ) \\
\hline \multicolumn{3}{|l|}{ Differences } \\
\hline Sample size & 388 & 81 \\
\hline Arithmetic mean (Bias) & -0.097 & -0.282 \\
\hline $95 \% \mathrm{Cl}$ & -0.236 to 0.042 & -0.619 to 0.056 \\
\hline Standard Error (SE) & 0.070829 & 0.1697 \\
\hline Standard deviation (Precision) & 1.3952 & 1.5278 \\
\hline Coefficient of variation (\%) & 11.8956 & 6.6932 \\
\hline Lower limit & -2.8312 & -3.2760 \\
\hline $95 \% \mathrm{Cl}$ & -3.0694 to -2.5930 & -3.856 to -2.696 \\
\hline Upper limit & 2.6379 & 2.7130 \\
\hline $95 \% \mathrm{Cl}$ & 2.3997 to 2.8761 & 2.133 to 3.293 \\
\hline
\end{tabular}

symphysis pubis. The system was also carefully checked for air bubbles.

Johna et al. [4] found that IBP did not reflect the actual IAP (limited up to $15 \mathrm{mmHg}$ ) during laparoscopic cholecystectomy. They concluded that further research is needed to identify potential variables that may affect the relationship between the urinary bladder and abdominal cavity pressures [4]. Regrettably, they limited their measurements to a maximum of $15 \mathrm{mmHg}$ for the sake of patients' safety in contrary to the recommendations of the World Society of Abdominal Compartment Syndrome (WSACS) [8]. Moreover, their methodology was criticized [5]. On the other hand, supporting evidence for the reliable use of bladder as an indirect method for measuring IAP came from Yol et al. who compared bladder pressure with insufflator pressure during laparoscopic cholecystectomy in 40 patients. They found a very good correlation between the two measurements $(r=0.973, p<$ 0.0001 ) [7]. Unfortunately, they also limited their measurements to a maximum of $15 \mathrm{mmHg}$ for the sake of patients' safety, and correlation coefficient was not the appropriate statistical test for comparing two methods of measurement $[8,11]$. Fusco et al. [6] measured IBP under different laparoscopic procedures with bladder volumes at $0,50,100$, 150 , and $200 \mathrm{ml}$ at IAP of $0.5,10,15,20$, and $25 \mathrm{mmHg}$. They concluded that IBP closely approximates IAP and that instillation of $50 \mathrm{ml}$ of fluid into the bladder improved the accuracy of the IBP at higher intra-abdominal pressures.

Techniques of simulating increased IAP via instillation of normal saline or insufflation of carbon dioxide as in laparoscopy are considered artificial environments that are far from being ideal, which make it difficult to validate indirect IAP measurements methods and extrapolating them to critically ill patients [15]. Laparoscopy may not reflect the situation of the original pathology that caused IAH, and pressure measurements may not be reliable in patients who have respiratory distress, sepsis with capillary leak, fluid overload, ascites or bladder infection, and may be contraindicated in patients who had bladder surgery or trauma.

Table 3 Cronbach's Alpha "Estimate of internal consistency" for All measurements: IAP \& IBP for all measures (IAP =0-22 mmHg) Versus measures for High IAP (IAP> $12 \mathrm{mmHg}$ )

\begin{tabular}{lllll}
\hline & & IAP $=0-22 \mathrm{mmHg}$ & IAP $>12-22 \mathrm{mmHg}$ & IAP $>20-22 \mathrm{mmHg}$ \\
\hline Case Processing Summary & Valid & 388 & 81 & 12 \\
& Excluded & 0 & 307 & 376 \\
& Total & 38 & 388 & 388 \\
\multirow{5}{*}{ Item Statistics } & Mean IAP & 388 & 21.3312 \\
& Mean IBP & 8.2542 & 16.1732 & 22.4345 \\
& Standard Deviation IAP & 8.3509 & 16.4547 & .54325 \\
Reliability Statistics & Standard Deviation IBP & 5.19970 & 3.02496 & 1.23482 \\
& Cronbach's Alpha & 5.41462 & 3.97039 & .787 \\
& Cronbach's Alpha Based on Standardized Items & .982 & .951 & .983 \\
\hline
\end{tabular}


Bladder compliance varies within and between patients. Larger instillation volumes may cause overestimation of IAP. Therefore, small volumes to a maximum of $25 \mathrm{ml}$, enough to create a fluid column and to remove air should be used [16]. The new WSACS guidelines recommend the use of $25 \mathrm{ml}$ of sterile saline in adults and $1 \mathrm{ml} / \mathrm{kg}$ (minimum $3 \mathrm{ml}$ - maximum $25 \mathrm{ml}$ ) in children [17]. In our study we used the older WSACS recommendation [9] of $50 \mathrm{ml}$ sterile saline to prime the urinary bladder. Our goal was to gradually insufflate $\mathrm{CO}_{2}$ intra-peritoneally to approximately $22 \mathrm{mmHg}$ to avoid any deleterious effects on patients' hemodynamics.

Care must be taken when interpreting the results that compare different methods of measurements. Such methods are occasionally analyzed inappropriately by using correlation coefficients or regression analysis, which are often misleading if used alone. Correlation coefficient measures the strength of a relation (correlation) between two variables, not the agreement between them [8]. According to Bland and Altman [11], "It would be amazing if two methods designed to measure the same quantity were not correlated". Therefore, the test of significant correlation is irrelevant to the question of agreement. The WSACS recommend the use of Bland-Altman analysis as an alternative approach to assess the limits of agreement between the two methods, that is how much the new method under assessment is likely to differ from the old or standard one [8, 11]. If this is accepted clinically, we can replace the old standard method by the indirect new one. How far apart measurements can be accepted clinically is a question of judgment, which depends on the clinical context, i.e. would the $95 \%$ limits of agreement between the two measurement methods meaningfully affect the interpretation of the results? [18]. Good agreement between two methods, as recommended by the WSACS, is defined as follows: the mean difference between the two measurements (bias) does not exceed $1 \mathrm{mmHg}$; the precision (the standard deviation of the bias) is not greater than2 $\mathrm{mmHg}$ and the $95 \%$ limits of agreement lies between \pm $4 \mathrm{mmHg}$, and a maximal percentage error of $25 \%$ [8]. The percentage difference or the coefficient of variation (defined as the precision divided by mean IAP (= $11.757 \%$ in our study) should also be provided, and be no higher than 15-20\% [8].

In our study, the Bland-Altman analysis indicates that the mean difference (bias) was -0.09668 , the precision was 1.3952 , and the $95 \%$ limits of agreement between the two methods ranged from -2.83 to 2.64. This indicates a high level of agreement between the two methods and we came to the same conclusion, as Fusco et al., that IBP closely approximates IAP.

LCCC between the two measurements was 0.965 (95\% confidence interval: 0.958-0.971) (Table 1). This shows a "substantial" strength of agreement based on the descriptive scale suggested by McBride for interpreting LCCC [13]. Internal consistency as demonstrated by Cronbach's alpha was generally excellent (Cronbach's alpha $=.95-.98)$. This has a high implication clinically because our aim is to evaluate high-risk patients for the early detection of IAH.

Furthermore, we calculated the correlation coefficient, Lin's concordance correlation, Cronbach's alpha and Bland-Altman analysis for IAP higher than $12 \mathrm{mmHg}$ as a subgroup (20.9\% of all measurements) (Tables 1, 2 and 3, Figs. 1 and 2). Although it was not as evident in Lin's concordance correlation [LCCC $=0.90]$, perhaps because of lack of agreement on the interpretation of LCCC for strength of agreement, Cronbach's alpha and Bland-Altman method plot showed evidence that Intra bladder pressure measurements for IAH were also reliable for detecting higher levels of IAP. The fact that LCC showed a "moderate" strength of agreement for high readings based on the descriptive scale suggested by McBride [13] makes it less reliable, according to McBride, for the early detection of intra-abdominal hypertension. Although Cronbach's alpha showed an excellent internal consistency, it was only acceptable (Cronbach's alpha $=.79$ ) for very high pressures (IAP > $20 \mathrm{mmHg}, 20.9 \%$ of all measurements), probably because of the few measurements taken at that range.

We did not try IAPs higher than $23 \mathrm{mmHg}$ in our study. We felt it would be unethical to jeopardize our patients' safety for the sake of the study.

There are some limitations to our study. Firstly, we recruited normal subjects, undergoing laparoscopic cholecystectomy, and subjected them to a situation that may resemble IAH. According to the recommendations of the WSACS, patients with at least two risk factors for IAH should be considered for the study [9]. In addition, the new recommendations of WSACS [17], namely the amount of saline instilled into the urinary bladder, the use of mid-axillary line for zero balancing should be taken into consideration. Secondly, in contrary to the relatively slow development of ACS, the time given for each measurement was relatively short due to the rapidity of gas insufflation and the continuous nature of recording the increments in IAP and IBP. Thirdly, the WSACS recommended that at least 50\% (later adjusted to one third) of measurements with an elevated IAP (12 $\mathrm{mmHg}$ or more), and at least $5 \%$ of the measurements with grade III IAH $(20-25 \mathrm{mmHg})[9,10]$. In our study, 388 simultaneous pressure measurements from all 21 patients were recorded at varying IAPs. Out of these pressure measurements, $20.9 \%$ were above $12 \mathrm{mmHg}$ (IAH) and $3.1 \%$ were above $20 \mathrm{mmHg}$ (grade III IAH). The relatively infrequent high-pressure recordings above 
$20 \mathrm{mmHg}$ in our study were due to unintentional abdominal manipulation. Fourthly, pressure measurements were recorded with the patients completely relaxed under general anesthesia patients, irrespective of the phase of respiratory cycle and gastric deflation by a naso-gastric tube. We assumed that any change in IAP caused by increased intra-thoracic or intra-gastric pressures would be accompanied by a synchronous increase in both IAP and IBP. This view is supported by Yol et al. [8], who found that when air was infused into the stomach via a nasogastric tube, the IAP and IBP increased simultaneously. Likewise, when the stomach was deflated, the two pressures decreased simultaneously to the pre-insufflation levels. Finally, Patients with higher body mass index (BMI) have higher resting intra-abdominal pressure which may stress the bladder and pelvic floor. Although there is a positive correlation between IAP and BMI, we assumed that it will affect both intra-abdominal and intra-bladder pressures equally. Nevertheless, BMI could be a confounding factor that was not considered in our study.

\section{Conclusion}

Although not fully compliant with WSACS recommendations, our study showed that IBP measurement is a simple, minimally invasive method that may reliably estimates IAP in patients placed in supine position. Measurements for pressures higher than $12 \mathrm{mmHg}$ may be less reliable. When applied clinically, this should alert the clinician to take safety measures to avoid abdominal compartment syndrome (ACS).

\section{Highlights}

Intra-abdominal Hypertension (IAH) is defined as an intra-abdominal pressure (IAP) equal to or above $12 \mathrm{mmHg}$ and abdominal compartment syndrome (ACS) is defined as an IAP above $20 \mathrm{mmHg}$ with evidence of organ dysfunction/failure. Clinically, significant intra-abdominal hypertension may be present in the absence of abdominal distension. Increased IAP is commonly measured by recording urinary bladder pressure. This study shows that urinary bladder pressure measurement is a simple, minimally invasive method that reliably estimates IAP. Urinary bladder pressure measurement can be used clinically to evaluate high-risk patients for the early detection of IAH and alert the clinician to take safety measures to avoid abdominal compartment syndrome (ACS).

\section{Abbreviations}

ACS: Abdominal compartment syndrome; BMI: Body mass index; $\mathrm{CO}_{2}$ : Carbon dioxide; IAH: Intra-abdominal hypertension; IAP: Intra-abdominal pressure; IBP: Intra-bladder pressure; LCCC: Lin' concordance correlation coefficient; SPSS: Statistical package for the social sciences 20; WSACS: The World Society of Abdominal Compartment Syndrome

\section{Acknowledgements}

The authors acknowledge the assistance of Computer Eng. Amatulrahman Al-Abassi and Biomedical Eng. Amatulraheem Al-Abassi for their helpful comments during the preparation of this manuscript in addition to English language editing and rearranging the references according to the Vancouver style.

We also thank the Medical District of Ras Al Khaimah and Saqr Hospital Administration for making pressure catheters available for study purposes, free of charge.

\section{Availability of data and materials}

The datasets used and analyzed during the current study are available from the corresponding author on reasonable request.

\section{Authors' contributions}

All three authors made substantial contributions to conception and design, acquisition of data, analysis and interpretation of data; The first two authors are surgeons who prepared the patients for surgery and took appropriate consents for the study. The third author, a Senior Uro-dynamics Technician, was responsible for preparing the required instruments and calibrating the tubings for measuring and recording intra-abdominal and intra-bladder pressures. All three authors have been involved in drafting the manuscript and revising it critically for data analysis and important intellectual content; All three authors contributed to the preparation, reading and approving the final manuscript and gave final approval of the version to be published; and All three authors agreed to be accountable for all aspects of the work in ensuring that questions related to the accuracy or integrity of any part of the work are appropriately investigated and resolved. All three authors read and approved the "final revised manuscript".

\section{Ethics approval and consent to participate}

This study was conducted at Saqr Hospital, Ras Al Khaimah, United Arab Emirates, in accordance with the study protocol approved by the hospital research ethics committee. All patients consented for participation in the study and agreed for publishing study results in medical journals.

\section{Competing interests}

The authors declare that they have no competing interests.

\section{Publisher's Note}

Springer Nature remains neutral with regard to jurisdictional claims in published maps and institutional affiliations.

\section{Author details}

'Department of Surgery, Saqr Hospital, Ras Al Khaimah, United Arab Emirates. 2Department of Urology, Saqr Hospital, Ras Al Khaimah, United Arab Emirates.

Received: 31 October 2017 Accepted: 1 June 2018

Published online: 19 June 2018

\section{References}

1. Cheatham ML, Malbrain ML, Kirkpatrick A, et al. Results from the international conference of experts on intra-abdominal hypertension and abdominal compartment syndrome. II Recommendations. Intensive Care Med. 2007;33(6):951-62. Epub 2007 Mar 22

2. Gudmundsson FF, Viste A, Gislason H, Svanes K. Comparison of different methods for measuring intra-abdominal pressure. Intensive Care Med. 2002; 28(4):509-14. Epub 2002 Jan 15

3. Obeid F, Saba A, Fath J, Guslits B, Chung R, Sorensen V, Buck J, Horst M. Increases in intra-abdominal pressure affect pulmonary compliance. Arch Surg. 1995;130(5):544-7. discussion 547-8

4. Johna S, Taylor E, Brown C, Zimmerman G. Abdominal compartment syndrome: does intra-cystic pressure reflect actual intra-abdominalpressure? A prospective study in surgical patients. Crit Care. 1999;3(6):135-8.

5. Malbrain ML. Different techniques to measure intra-abdominal pressure (IAP): time for a critical re-appraisal. Intensive Care Med. 2004;30(3):357-71. Epub 2004 Jan 17

6. Fusco MA, Martin RS, Chang MC. Estimation of intra-abdominal pressure by bladder pressure measurement: validity and methodology. J Trauma. 2001; 50(2):297-302 
7. S Y, Kartal A, Tavli S, Tatkan Y. Is urinary bladder pressure a sensitive indicator of intra-abdominal pressure? Endoscopy. 1998;30(9):778-80.

8. De Waele JJ, Cheatham ML, Malbrain ML, et al. Recommendations for research from the international conference of experts on intra-abdominal hypertension and abdominal compartment syndrome. ActaClin Belg. 2009; 64(3):203-9.

9. WSACS Recommendations for Research: https:/www.wsacs.org/research/ recommendations-for-research.html [Accessed 14 Apr 2014].

10. Lin L. A concordance correlation coefficient to evaluate reproducibility. Biometrics. 1989:45:255-68.

11. Bland JM, Altman DG. Statistical methods for agreement between two methods of clinical measurement. Lancet. 1986;1 (8476):307-10.

12. Cronbach L. Coefficient alpha and the internal structure of tests. Psychomerika. 1951;16:297-334. https://doi.org/10.1007/BF02310555.

13. McBride G. A proposal for strength-of-agreement criteria for Lin's concordance correlation coefficient. In: NIWA client report: HAM2005-062 report to Ministry of Health; 2005. https://www.medcalc.org/download/pdf/ McBride2005.pdf. Approached on 06 June 2018.

14. De Waele JJ, Billiet E, Hoste E, Colardyn F. The assumed problem of air bubbles in the tubing during intra-abdominal pressure measurement. Intensive Care Med. 2004;30(8):1692. author reply 1693. Epub 2004 May 28

15. Malbrain M. (2007). The pathophysiologic implications of intra-abdominal hypertension in the critically ill. https://www.researchgate.net/profile/Manu_ Malbrain2/publication/313823942_The_pathophysiologic_implications_of_ intra-abdominal_hypertension_in_the_critically_ill/links/ 58a8114faca27206d9ac4afo/The-pathophysiologic-implications-of-intraabdominal-hypertension-in-the-critically-ill.pdf?origin=publication_detail [Accessed 2 May 2018].

16. Malbrain ML, Deeren DH. Effect of bladder volume on measured intravesical pressure: a prospective cohort study. Crit Care. 2006;10(4):R98

17. Kirkpatrick AW, Roberts DJ, De Waele J, Jaeschke R, Malbrain ML, De Keulenaer B, Duchesne J, Bjorck M, Leppaniemi A, Ejike JC, Sugrue M, Cheatham M, Ivatury R, Ball CG, Reintam Blaser A, Regli A, Balogh ZJ, D'Amours S, Debergh D, Kaplan M, Kimball E, Olvera C. The pediatric guidelines sub-committee for the world society of the abdominal compartment syndrome. Intra-abdominal hypertension and the abdominal compartment syndrome: updated consensus definitions and clinical practice guidelines from the World Society of the Abdominal Compartment Syndrome. Intensive Care Med. 2013;39(7):1190-206. https://doi.org/10.1007/ s00134-013-2906-z. Epub 2013 May 15

18. Myles PS, Cui J. Using the bland Altman method to measure agreement with repeated measures. Br J Anaesth. 2007;99(3):309-11.

\section{Ready to submit your research? Choose BMC and benefit from:}

- fast, convenient online submission

- thorough peer review by experienced researchers in your field

- rapid publication on acceptance

- support for research data, including large and complex data types

- gold Open Access which fosters wider collaboration and increased citations - maximum visibility for your research: over $100 \mathrm{M}$ website views per year

At BMC, research is always in progress.

Learn more biomedcentral.com/submissions 